\title{
Malaria Diagnostics, Where are we Now
}

\author{
DC Ghislaine Mayer ${ }^{1}$, Luke Dixon ${ }^{2}$ and Johanna M Porter-Kelley² \\ ${ }^{1}$ Department of Biology, Manhattan College, USA
}

${ }^{2}$ Department of Life Sciences, Winston Salem State University, USA

"Corresponding author: Johanna Porter-Kelley, Department of Life Sciences, Winston Salem State University, 601 Martin Luther King Dr., Winston Salem, NC 27107,USA, Tel: 336-750-3239; Fax: 336-750-3094; E-mail: porterkelleyj@wssu.edu

Received date: March 28, 2014, Accepted date: April 24, 2014, published date: April 26, 2014

Copyright: (c) 2014 Porter-Kelly JM, et al. This is an open-access article distributed under the terms of the Creative Commons Attribution License, which permits unrestricted use, distribution, and reproduction in any medium, provided the original author and source are credited.

\section{Introduction}

Malaria, a worldwide disease of high morbidity and mortality, causes over 1 million deaths per year, mostlyin children less than 5 years of age $[1,2]$. Delayed treatment of malaria increases the chances of death and neurological disease [3]. In addition, to bring about malaria eradication and prolong accumulation of drug resistant parasites, treatment must follow an accurate diagnosis. To that end, a major goal in malaria diagnostics is to develop assays that are both sensitive and cost-effective for use in developing countries, which are economically and infrastructurally challenged. This review analyzes the current state of malarial diagnostics, from the gold standard of Giemsa-stained blood smears for microscopic examination to highly sensitive and novel technologies. Here, we suggest a future direction for malarial diagnostics.

\section{Optical Imaging Techniques}

Developed in the 1900s, microscopic examination of both thick and thin Giemsa-stained blood smears have long been the gold standard for malaria diagnosis [4]. Well trained microscopist can identify the species of the infecting Plasmodium parasite and quantify the density of parasite burden. Identification of the Plasmodium species and parasite density is necessary to determine the best treatment and subsequent monitoring of treatment success.Optimally, microscopic detection of parasitemia can measure as low as 5 parasites/ $\mu$ or $0.0001 \%$ on thick smear; which is not sensitive enough to detect parasitemias in low transmission areas. Although this is the standard procedure, good quality staining reagents and microscopes, as well as, well trained microscopists are needed for this diagnostic technique, all of which developing countries may have a difficultymaintaining [3]. Microscopic diagnostic methods are also limited by the lack of a universal standard for quantifying parasites[4].There are other techniques that can enhance microscopic techniques by concentrating the parasites in heparinized blood smears or the quantitative buffycoat method [3].

Diagnostic techniques utilizing alternative stains, such as Field's stain, acridine orange, or benzothiocarboxypurine have also been developed. Field's stain is a water-based Romanovsky stain that produces results that are comparable to that of Giemsa, however, the stain fades and is not available for review. Acridine orange and benzothiocarboxypurine users claim that these stains are easier to read and do not require an experienced microscopist. Nonetheless, these stains require a fluorescent microscope which may not be feasible in an isolated area lacking reliable electricity $[4,5]$.

Diagnoses of malaria have also been conducted using dark-field and polarization microscopy. Jamjoom [6] showed that dark-field microscopy could be used for rapid detection of malaria or hemozoin pigment [6-8]. Polarization microscopy also detects malaria pigment in infected red blood cells compared to healthy red blood cells. It appears that these other light microscopy techniques may have a higher detection rate than Giemsa-stained blood smears with a simple compound microscope, although there is some problem with formalin pigment producing artifacts which may be mistaken as malaria pigment [9].

\section{Molecular Techniques}

While microscopy remains the most widely used method for diagnosing malaria, methods based on the polymerase chain reaction (PCR) of the small subunit ribosomal RNA gene (18SSU rRNA) were more recently developed. PCR based techniques are capable of detectingparasites at submicroscopic levels, quantifying the parasitic load, and identifying the species of Plasmodium responsible for the disease [10-12]. Moreover, in many cases, the sensitivity of PCR allows detection of asymptomatic or sub-clinical cases of malaria [13].

The gold standard among the PCR-driven malaria diagnostics, nested PCR is certainly the best established andinstrumental in detecting co-infections, which are prevalent in malaria-endemic areas [14-16]. Despite its success, well-trained laboratory personnel, high risk of contamination, and a lengthy process are drawbacks to its use. To circumvent these problems, a semi-nested PCR protocol was recently developed by Ongagna-Yhombi and colleagues using primers targeting the P. falciparumdihydrofolatereductase gene amplified from saliva of malaria infected patients [17].

Moreover, multiplex PCR and quantitative real-time PCR (qPCR) have also been proposed as potential tools for the diagnosis of clinical malaria $[18,19]$. Both multiplex and qPCR have the capacity to detect multiple Plasmodium species in a single reaction and $\mathrm{qPCR}$ can determine parasite loads at submicroscopic levels of parasites $[18,19]$.

The loop-attenuated isothermal amplification (LAMP), a single cycle method that avoids the pitfalls of nested PCR, targets mitochondrial DNA [20-22]. Although LAMP has been proposed as a viable technique for malaria surveillance and has the advantage of being able to obtain more rapid results, it has not yet been established as a viable diagnostic tool that could be used on large number of samples in surveillance studies.Despite the recent advances in molecular techniques, the use of PCR-based methods for routine diagnosis of malaria remains elusive in endemic areas because of cost and the need for highly trained laboratory technicians.

\section{Rapid Diagnostic Test}

Rapid diagnostic tests (RDTs) utilize antibodies to detect Plasmodium-specific antigens from the peripheral blood circulation in 
as little as 10 to $15 \mathrm{~min}$. The majority of commercially available RDTs target histidine-rich protein-2 (HRP-2), a protein specific to the P. falciparum species, Plasmodium-lactate dehydrogenase $(\mathrm{pLDH})$ or Plasmodiumadolase, enzymes found in the glycolytic pathway of all five Plasmodium spp. known to infect humans [23].

Recent studies of the diagnostic efficacy of microscopy, real-time qPCR, and PfHRP-2 / pLDH ELISA for identifying Plasmodium parasites found that PfHRP-2 ELISA detected malarial prevalence comparable to that of qPCR [24]. While PfHRP-2 RDTs have displayed a high degree of sensitivity and specificity, they are not without their limitations. An antigen specific to P. falciparum, HRP-2 is not suitable for the detection of other Plasmodium spp. known to infect humans [25]. Genetic deletions of pfhrp2 and pfhrp3 genes, has been reported in Peru [26,27], Brazil [28], Mali [29], and India [30]. Although HRP-2 has been detected weeks after the cessation of symptoms [25], pLDH is only produced by viable Plasmodium spp. [31], and therefore, pLDH RDTs have the capacity to not only assess current parasitemias but also the efficacy of antimalarial therapies [32,33]. pLDH-based tests have also displayed similar specificity to HRP-2 assays (98\%), albeit lower sensitivity (67\%), in detecting P. falciparum infections in endemic areas [34]. However, pLDH RDTs have recently shown an inability to accurately identify mixed infections of parasites ( $P$. falciparum, P. vivax, and P. knowlesi) [35-37].

\section{Conclusion}

Considering the state of malaria worldwide our efforts toward an accurate diagnosis malaria and treatment are lacking. Some antimalarial treatment is delivered based onclinical diagnosis (febrile patients) in which the patient may or may not have malaria, but some other disease with similar symptoms. Diagnostic methods are used that are not sensitive enough to detect low parasitemias. Infrastructure, finance, and trained personnel needed for accurate diagnosis is lacking in endemic areas. A major goal in malaria diagnostics is development of assays that are both sensitive and costeffective for use in developing countries, which are economically and infrastructurally challenged. The gold standard of Giemsa-stained blood smears for microscopic examination and RDTs aresufficient to detect case of malaria in high transmission areas in patients with no immunity $[3,34]$. However, persons with immunity to malaria and are asymptomatic have low level parasitemiaswhich are not diagnosed and remain untreated, contributing to malaria transmission. Without a sensitive inexpensive diagnostic test for persons immune to malaria and those living in a low transmission areas, eradication of malaria will be less feasible [13]. Molecular tools are too expensive, complex and not rapid.Ideally, to eradicate malaria, curtail the overuse of expensive anti-malarial and the build-up of resistance to our depleted antimalarial arsenal; we recommend antimalarial treatment, only for patients in casesthat have a positive laboratory diagnosis for malaria. Patient samples found to be negative by microscopy or RDT should be screened by molecular techniques to discover low levels of parasitemias. If parasite burden is needed, microscopy should be used for detectable counts and qPCR should be used for low level burden. Nevertheless, in the real world, a highly sensitive economical test would yield a giant step toward malaria eradication.

\section{References}

1. Breman JG (2001) The ears of the hippopotamus: manifestations, determinants, and estimates of the malaria burden. Am J Trop Med Hyg 64: 1-11.
2. Snow RW, Craig M, Deichmann U, Marsh K (1999) Estimating mortality, morbidity and disability due to malaria among Africa's nonpregnant population. Bull World Health Organ 77: 624-640.

3. Bronzan RN, McMorrow ML, Kachur SP (2008) Diagnosis of malaria: challenges for clinicians in endemic and non-endemic regions. Mol DiagnTher 12: 299-306.

4. Makler MT, Palmer CJ, Ager AL (1998) A review of practical techniques for the diagnosis of malaria. Ann Trop Med Parasitol 92: 419-433.

5. Okell LC, Ghani AC, Lyons E, Drakeley CJ (2009) Submicroscopic infection in Plasmodium falciparum-endemic populations: a systematic review and meta-analysis. J Infect Dis 200: 1509-1517.

6. Jamjoom GA (1983) Dark-field microscopy for detection of malaria in unstained blood films. J ClinMicrobiol 17: 717-721.

7. Jamjoom GA (1991) Improvement in dark-field microscopy for the rapid detection of malaria parasites and its adaptation to field conditions. Trans R Soc Trop Med Hyg 85: 38-39.

8. Wilson BK, Behrend MR, Horning MP, Hegg MC (2011) Detection of malarial byproduct hemozoin utilizing its unique scattering properties. Opt Express 19: 12190-12196.

9. Romagosa C, Menendez C, Ismail MR, Quintó L, Ferrer B, et al. (2004) Polarisation microscopy increases the sensitivity of hemozoin and Plasmodium detection in the histological assessment of placental malaria. Acta Trop 90: 277-284.

10. Snounou G, Viriyakosol S, Jarra W, Thaithong S, Brown KN (1993) Identification of the four human malaria parasite species in field samples by the polymerase chain reaction and detection of a high prevalence of mixed infections. Mol BiochemParasitol 58: 283-292.

11. Kimura M, Kaneko O, Liu Q, Zhou M, Kawamoto F, et al. (1997) Identification of the four species of human malaria parasites by nested PCR that targets variant sequences in the small subunit rRNA gene. Parasitolint 46: 91-95.

12. Win TT, Lin K, Mizuno S, Zhou M, Liu Q, et al. (2002) Wide distribution of Plasmodium ovale in Myanmar. Trop Med Int Health 7: 231-239.

13. Berry A, Fabre R, Benoit-Vical F, Cassaing S, Magnaval JF (2005) Contribution of PCR-based methods to diagnosis and management of imported malaria. Med Trop (Mars) 65: 176-183.

14. malERA Consultative Group on Diagnoses and Diagnostics (2011) A research agenda for malaria eradication: diagnoses and diagnostics. PLoS Med 8: e1000396.

15. Snounou G, Singh B (2002) Nested PCR analysis of Plasmodium parasites. Methods Mol Med 72: 189-203.

16. Singh B, Bobogare A, Cox-Singh J, Snounou G, Abdullah MS, et al. (1999) A genus- and species-specific nested polymerase chain reaction malaria detection assay for epidemiologic studies. Am J Trop Med Hyg 60: 687-692.

17. Ongagna-Yhombi SY, Corstjens P, Geva E, Abrams WR, Barber CA, et al. (2013) Improved assay to detect Plasmodium falciparum using an uninterrupted, semi-nested PCR and quantitative lateral flow analysis. Malar J 12: 74

18. Mangold KA, Manson RU, Koay ES, Stephens L, Regner M, et al. (2005) Real-time PCR for detection and identification of Plasmodium spp. J ClinMicrobiol 43: 2435-2440.

19. Kamau E, Alemayehu S, Feghali KC, Saunders D, Ockenhouse CF (2013) Multiplex qPCR for detection and absolute quantification of malaria. PLoS One 8: e71539.

20. Paris DH, Imwong M, Faiz AM, Hasan M, Yunus EB, et al. (2007) Loopmediated isothermal PCR (LAMP) for the diagnosis of falciparum malaria. Am J Trop Med Hyg 77: 972-976.

21. Scott CS, Van Zyl D, Ho E, Ruivo L, Mendelow B, et al. (2002) Thrombocytopenia in patients with malaria: automated analysis of optical platelet counts and platelet clumps with the Cell Dyn CD4000 analyser. Clin Lab Haematol 24: 295-302.

22. Fawzi ZO, Fakhro NA, Nabhan RA, Alloueche A, Scott CS (2003) Differences in automated depolarization patterns of Plasmodium 
Citation: Porter-Kelley JM, Dixon L, Mayer DCG, et al. (2014) Malaria Diagnostics, Where are we Now. Trop Med Surg 2: 169. doi: 10.4172/2329-9088.1000169

Page 3 of 3

falciparum and P. vivax malaria infections defined by the Cell-Dyn CD4000 haematologyanalyser. Trans R Soc Trop Med Hyg 97: 71-79.

23. Moody A (2002) Rapid diagnostic tests for malaria parasites. ClinMicrobiol Rev 15: 66-78.

24. Bashir IM, Otsyula N, Awinda G, Spring M, Schneider P, et al. (2013) Comparison of PfHRP-2/pLDH ELISA, qPCR and microscopy for the detection of plasmodium events and prediction of sick visits during a malaria vaccine study. PLoS One 8: e56828.

25. Hawkes M, Kain KC (2007) Advances in malaria diagnosis. Expert Rev Anti Infect Ther 5: 485-495.

26. Gamboa D, Ho MF, Bendezu J, Torres K, Chiodini PL, et al. (2010) A large proportion of $\mathrm{P}$. falciparum isolates in the Amazon region of Peru lack pfhrp2 and pfhrp3: implications for malaria rapid diagnostic tests. PLoS One 5: e8091.

27. Maltha J, Gamboa D, Bendezu J, Sanchez L, Cnops L, et al. (2012) Rapid diagnostic tests for malaria diagnosis in the Peruvian Amazon: impact of pfhrp2 gene deletions and cross-reactions. PLoS One 7: e43094.

28. Houzé S, Hubert V, Le Pessec G, Le Bras J, Clain J (2011) Combined deletions of pfhrp2 and pfhrp3 genes result in Plasmodium falciparum malaria false-negative rapid diagnostic test. J ClinMicrobiol 49: 2694-2696.

29. Koita OA, Doumbo OK, Ouattara A, Tall LK, Konaré A, et al. (2012) False-negative rapid diagnostic tests for malaria and deletion of the histidine-rich repeat region of the hrp2 gene. Am J Trop Med Hyg 86: 194-198.

30. Kumar N, Pande V, Bhatt RM, Shah NK, Mishra N, et al. (2013) Genetic deletion of HRP2 and HRP3 in Indian Plasmodium falciparum population and false negative malaria rapid diagnostic test. Acta Trop 125: $119-121$
31. Marx A, Pewsner D, Egger M, Nüesch R, Bucher HC, et al. (2005) Metaanalysis: accuracy of rapid tests for malaria in travelers returning from endemic areas. Ann Intern Med 142: 836-846.

32. Jang JW, Cho CH, Han ET, An SS, Lim CS (2013) pLDH level of clinically isolated Plasmodium vivax and detection limit of pLDH based malaria rapid diagnostic test. Malar J 12: 181.

33. Aydin-Schmidt B, Mubi M, Morris U, Petzold M, Ngasala BE, et al. (2013) Usefulness of Plasmodium falciparum-specific rapid diagnostic tests for assessment of parasite clearance and detection of recurrent infections after artemisinin-based combination therapy. Malar J 12:349.

34. Ochola LB, Vounatsou P, Smith T, Mabaso ML, Newton CR (2006) The reliability of diagnostic techniques in the diagnosis and management of malaria in the absence of a gold standard. Lancet Infect Dis 6: 582-588.

35. Pakalapati D, Garg S, Middha S, Kochar A, Subudhi AK, et al. (2013) Comparative evaluation of microscopy, OptiMAL ${ }^{\circ}$ and $18 \mathrm{~S}$ rRNA gene based multiplex PCR for detection of Plasmodium falciparum\&Plasmodium vivax from field isolates of Bikaner, India. Asian Pac J Trop Med 6: 346-351.

36. Barber BE, William T, Grigg MJ, Piera K, Yeo TW, et al. (2013) Evaluation of the sensitivity of a pLDH-based and an aldolase-based rapid diagnostic test for diagnosis of uncomplicated and severe malaria caused by PCR-confirmed Plasmodium knowlesi, Plasmodium falciparum, and Plasmodium vivax. J ClinMicrobiol 51: 1118-1123.

37. Foster D, Cox-Singh J, Mohamad DS, Krishna S, Chin PP, et al. (2014) Evaluation of three rapid diagnostic tests for the detection of human infections with Plasmodium knowlesi. Malar J 13: 60. 